\title{
AMENDMENTS
}

\section{Author Correction: Full-length mRNA-Seq from single-cell levels of RNA and individual circulating tumor cells}

Daniel Ramsköld, Shujun Luo, Yu-Chieh Wang, Robin Li, Qiaolin Deng, Omid R. Faridani, Gregory A. Daniels, Irina Khrebtukova, Jeanne F. Loring, Louise C. Laurent, Gary P. Schroth and Rickard Sandberg

Correction to: Nature Biotechnology https://doi.org/10.1038/nbt.2282, published online 22 July 2012.

In the version of this article initially published, the recipient of grant RN2-00931 from the California Institute for Regenerative Medicine was listed as J.F.L. The correct recipient is L.C.L. The error has not been corrected in the original article.

Published online: 3 February 2020

https://doi.org/10.1038/s41587-020-0427-1

(๑) The Author(s), under exclusive licence to Springer Nature America, Inc. 2020

\section{Publisher Correction: OpenSWATH enables automated, targeted analysis of data-independent acquisition MS data}

Hannes L. Röst, George Rosenberger, Pedro Navarro, Ludovic Gillet, Saša M. Miladinović, Olga T. Schubert, Witold Wolski, Ben C. Collins, Johan Malmström, Lars Malmström and Ruedi Aebersold

Correction to: Nature Biotechnology https://doi.org/10.1038/nbt.2841, published online 10 March 2014.

In the version of this article initially published, the $y$-axis label in Fig. $2 \mathrm{~d}$ read "Coefficient of variation." The correct label is "Relative $\log$ (intensity)." The error has not been corrected in the original article.

Published online: 24 February 2020

https://doi.org/10.1038/s41587-020-0457-8

() Springer Nature America, Inc. 2020

\section{Retraction Note: Transient cytokine treatment induces acinar cell reprogramming and regenerates functional beta cell mass in diabetic mice}

Luc Baeyens, Marie Lemper, Gunter Leuckx, Sofie De Groef, Paola Bonfanti, Geert Stangé, Ruth Shemer, Christoffer Nord, David W. Scheel, Fong C. Pan, Ulf Ahlgren, Guoqiang Gu, Doris A. Stoffers, Yuval Dor, Jorge Ferrer, Gerard Gradwohl,

Christopher V. E. Wright, Mark Van de Casteele, Michael S. German, Luc Bouwens and Harry Heimberg

Retraction of: Nature Biotechnology https://doi.org/10.1038/nbt.2747, published online 17 November 2013.

The authors are retracting this paper owing to errors in the reported data. The paper claimed that treatment with a combination of epidermal growth factor and ciliary neurotrophic factor normalized glycemia and converted acinar cells to beta cells in $65 \%$ of hyperglycemic mice studied. However, these findings were not reproduced when the authors recently repeated the experiments. Reexamination by immunohistochemistry and genotyping of archived pancreas tissue samples from mice used in Baeyens et al. showed that the transgenic mice reported in Supplementary Figs. 3 and 6 and in Figs. 4 and 5 were misidentified, invalidating data central to the main claims of the paper.

Published online: 17 February 2020

https://doi.org/10.1038/s41587-020-0426-2

(c) The Author(s), under exclusive licence to Springer Nature America, Inc. 2020 